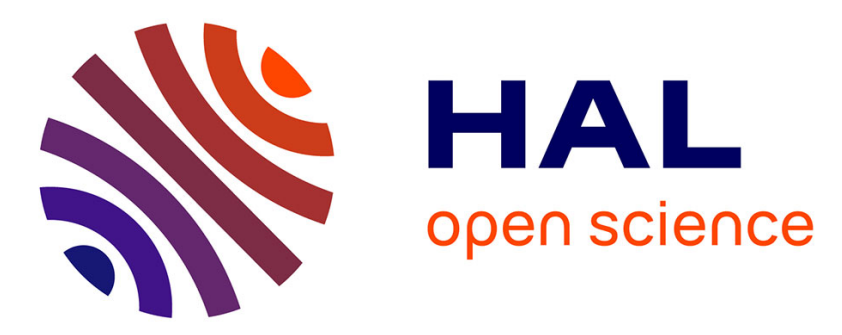

\title{
StimCards: interactive and configurable Question and Answer game - Users study conclusion
}

Céline Jost, Marine Grandgeorge, Brigitte Le Pévédic, Dominique Duhaut

\section{To cite this version:}

Céline Jost, Marine Grandgeorge, Brigitte Le Pévédic, Dominique Duhaut. StimCards: interactive and configurable Question and Answer game - Users study conclusion. IEEE Robio 2013, Robotics and Biomimetics, Dec 2013, China. hal-00880065

\section{HAL Id: hal-00880065 https://hal.science/hal-00880065}

Submitted on 5 Nov 2013

HAL is a multi-disciplinary open access archive for the deposit and dissemination of scientific research documents, whether they are published or not. The documents may come from teaching and research institutions in France or abroad, or from public or private research centers.
L'archive ouverte pluridisciplinaire HAL, est destinée au dépôt et à la diffusion de documents scientifiques de niveau recherche, publiés ou non, émanant des établissements d'enseignement et de recherche français ou étrangers, des laboratoires publics ou privés. 


\title{
StimCards: interactive and configurable Question and Answer game Users study conclusion
}

\author{
C. Jost, M. Grandgeorge, B. Le Pévédic, and D. Duhaut
}

\begin{abstract}
This paper highlights conclusions about six experiments conducted with StimCards, an interactive and configurable Question and Answer game. It has been created in the context of the Robadom project whose goal is to propose a homecare robot for seniors. In this project, StimCards is applied to cognitive stimulation. This game is special because users can create their own questions and their own game scripts, and decide which digital devices will be used to interact with. Two experiments have been realized to evaluate the possibility for users to create game scripts. Two other experiments compared children and seniors. They evaluated StimCards acceptability and the preferred users' computing interlocutor. Results showed that it is so easy to create game scripts that children can do it. Both children and seniors liked StimCards, and children preferred to interact with a robot, rather than a computer or a virtual character.
\end{abstract}

\section{INTRODUCTION}

$\mathrm{T}$ HE population is ageing, with less and less space in retirement home or healthcare home. Becoming a world problem, it urges to ensure seniors home support [1]. It is the main concern for the Robadom project [2] whose objective is to propose a homecare robot for seniors with cognitive disabilities. Among different tasks, the robot can offer cognitive stimulation exercises. The following questions appear: is it judicious to give this role to a robot? In which conditions can seniors accept a robot? Do people prefer to interact with a computer, a virtual character or another device? Indeed, a lot of new digital devices have appeared for a few years such as camera, micro, smartphone, and tablet. It is not obvious that robots are the favorite interlocutors. With the field of ubiquitous computing [3], it is now possible to interact with a set of objects: i.e. a digital environment. Thus, we created StimCards, an interactive and configurable Question and Answer game which can easily be connected with several input and output devices. We conducted six experiments to answer the questions above. Two experiments [4][5] previously evaluated AmbiProg, software which allows people to create game scripts. We hypothesized that people will accept StimCards more easily

Manuscript received August 31, 2013. This work has been supported by French National Research Agency (ANR) through TecSan program (Robadom project $\mathrm{n}^{\circ}$ ANR-09-TECS-012).

C. J. Author is with the Laboratory Lab-STICC , UMR 6285, ENIB, Brest, France (e-mail: celine.jost@gmail.com)

M.G. Author is with the Laboratory of Neurosciences of Brest, EA 4685 , University of Bretagne Occidentale, Brest, France (email: marine.grandgeorge@chu-brest.fr)

B.L.P. Author and D.D. Author are with the Laboratory Lab-STICC, UMR 6285, University of South Brittany, Vannes, if they participate to the system construction. Thus, it was important to check if the visual programming language (AmbiProg) was easily usable and understandable. Then, two experiments [6][7] compared children and seniors about their favorite companions. They interacted with a computer, a robot and a virtual character. Finally, two experiments compared children [8] and seniors acceptance. Figure 1 shows the contribution of this article which describes experiments about seniors' acceptance, compared to children's acceptance and gives general conclusions regarding all the six experiments.

The section II presents some clues provided by the state of the art arguing the importance of studying people acceptance and the interest to propose a game in such situation. The section III describes our solution: StimCards, an interactive game applied to cognitive stimulation. The section IV details the experiments realized to evaluate StimCards. Finally, the section $\mathrm{V}$ concludes the paper and gives some perspectives.

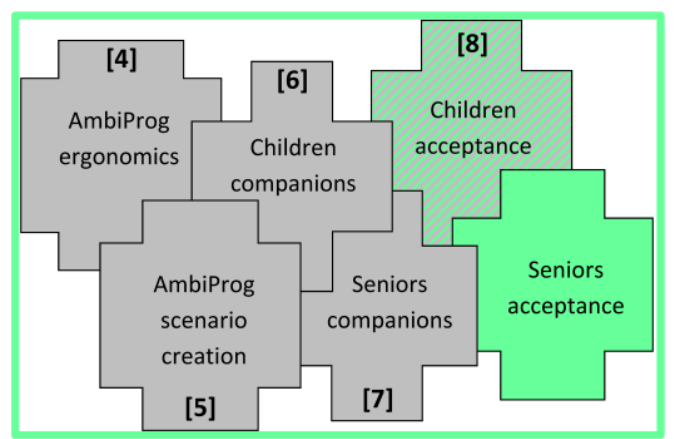

Fig. 1. The six experiments. The green color shows this paper contribution: seniors acceptance compared to children acceptance and general conclusions.

\section{BACKGROUND}

Our purpose is to provide StimCards to people. How can we ensure that it is a pertinent tool and that people have the willing to use it? To answer these questions, it is appropriate to look at acceptability [9]. It is crucial to take users' willing into account. One of the widely used model is the Technology Acceptance Model (TAM) [10]. It introduces the notions of "perceived usefulness" and "perceived ease of use", which seem to be decisive for users' attitude towards technology and for users' acceptance [11]. These both notions lead to "behavioral intention of use". Moreover, Vankatesh et al. [12] add the notion of intrinsic motivation which is determinant for behavioral intention to use a new technology. It means that a new technology must be easy to 
use, useful and not imposed to people. But even if TAM appears to be highly reliable [13], it particularly seems to be limited [10]. Indeed, human is not included in the conception, while "the human should be the core of the system" [14]. To our knowledge, there is no consensus about a model of acceptability, which is a vast and fast-growing domain [15]. For example, Tricot et al. [16] consider that it is not possible to speak about acceptability without taking utility and usability into account, while Pesty et al. [9] consider that a system is acceptable if it is "socially credible".

This state of the art highlights some essential characteristics for an accepted technology. The system must be reliable, simple and answer to users' needs [17], respecting their willing to use it [18]. Moreover, technology must ensure people's privacy and must not impose itself. For example, Rico et al. [19] enriched existing devices, ever used by people. They studied new gestures to interact with mobile phones, to obtain new services. This new interaction must be acceptable knowing that "acceptance of gestures is increased after even one positive experience". That means that a system is more easily accepted if it is familiar. For example, Fuchsburger [1] created the Internet Protocol Television (IPTV) which allows seniors accessing education. The television is a familiar object which acts against the seniors' loneliness. This study highlights that it is interesting to use existing devices to improve acceptance.

But it seems that technology acceptance depends on humans too. For example, Tacken et al [20] indicate that "people with low income and a low education level use new technologies less than people with a high income or a high education". It is contradicted by Heerink et al [21] who think that acceptability is not linked to social skills. A study [22] showed that people with Alzheimer's disease learnt how to interact with computers, although they never used it before. Tacken's results may be explained by the fact that new technologies prices are a problem [17]. Genders seem to impact acceptance too [23]: "men might consider perceived usefulness to a greater extent than women in making their decisions regarding the use of a new technology. Perceived ease of use is more salient to women compared with men".

Taken together, these studies suggest that user participation to the system conception and individualization are important. Thus, StimCards conception takes users into account. That is why each stage was evaluated, comparing children and seniors, female and male, to test a global acceptance and to test StimCards individualization.

However seniors remain a challenge. Being generally reluctant to use computers, they seem to be afraid that computers replace real people on the one hand. According to them, loneliness is the worst existing feelings and they need to feel helpful, to improve their mind and to stay connected to other people in the other hand [24]. Thus, it is a challenge to convince them that they can benefit from computers: they provide required training exercises and allow to communicate with their family and doctors, preventing loneliness [22].

To convince them, what about providing them a game? Indeed, Imbeault [25] specifies that digital games which combine training exercises and technology give more pleasure that paper games. Games seem therefore a good solution to do cognitive training because they give cognitive profit ensuring that gamers enjoy without making any effort [26]. Moreover games are interesting for learning process, often used in education [27]. Finally, games with therapeutic goals and social components have high benefits for seniors [28]. Taken together, it appears that games seem to be a good way towards acceptability whatever gender and age.

But, even if games can solve the acceptability challenge, two problems remain: lassitude feeling and attention loss. Indeed passivity can cause lassitude feeling and attention loss [29]. To avoid passivity, the computing system has to take human into account. People should actively contribute to the task and get an immediate positive feedback about their participation. In the Human-Computer Interaction domain, Goth [30] showed the end of Graphical User Interface (GUI) because users are too passive. The system combining mouth and keyboard is disappearing, replaced by new applications with more natural interactions, i.e. multimodal interaction [31]. The problem is that most of the recent games about cognitive stimulation or reeducation does not use new interaction techniques and cannot be adapted [8].

Considering this state of the art, building their own system appears essential to users. Acceptability can be improved using game system, which can use existing objects to interact with users. StimCards was created in this sense.

\section{STIMCARDS}

StimCards is an interactive and configurable Question and Answer game. In Robadom project, this game is applied to cognitive stimulation. It is interactive because some digital devices can be connected together to create different game structures. For example, StimCards can display data game on a computer, can support users with robots or virtual characters or can receive data from mobiles, tactile tablets and so on. It offers a totally personalized human-machine communication as users can choose their favorite modality to play a game. Moreover StimCards is configurable because users can create their own questions, determine the game structure according to the active digital devices, and create their own game scripts. StimCards is opened and can be enriched day after day.

\section{A. StimCards principles}

StimCards is composed of four kinds of elements: game cards with QR code and a camera as well as two optional elements: a Graphical User Interface and output devices, i.e. some digital devices which can be used as input devices or as companions.

To play, gamers must show a card QR code to the camera. The code is detected and decoded by a specific program. 
Each QR code contains a question, some suggested answers, a correct answer... The StimCards Graphical User Interface displays card data. Some robotic or virtual companions ask questions. If the card contains multiple-choice questions, gamers choose their answer among suggested answers. They uses mobile, tactile tablets or other input devices to send their answer. Figure 2 shows two StimCards organization examples. In both examples, StimCards Graphical User Interface displays questions data. On the left, two robots assist users. To answer, it is possible to directly use the keyboard or the Graphical User Interface. On the right, a robot assists users. It is possible to answer with the tactile tablet.

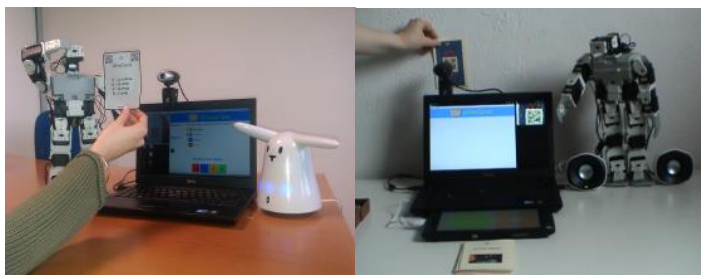

Fig. 2. StimCards organization example

\section{B. StimCards questions}

StimCards offers the possibility to create new personalized questions. Indeed, each game card is associated to a XML file, which is a configuration file. This configuration contains: the question and optionally an associated picture or sound file, a question type (e.g. multiple-choice question, open question), a card category (e.g. entertainment, sciences, math), colors (Graphical User Interface background, font), a set of clues which helps gamers, a set of suggested answers (e.g. text and/or picture and/or sound) and the true answer.

It is possible to add new questions in three stages. First, a XML file, describing the question, is created. Second, the question is encoded in a QR code. Third, a game card which contains the QR code is created.

\section{StimCards Graphical User Interface}

StimCards provides a Graphical User Interface which displays the XML file content. Figure 3 shows an example of a loaded card. Each data, except the true answer, is displayed. The figure shows a question with an associated picture. There are also four suggested answers composed of a text and a picture. An example of clue is displayed ("It can be very precious"). The different police names, sizes and colors are contained in the XML file too. The four answer buttons can be used directly by users to answer the

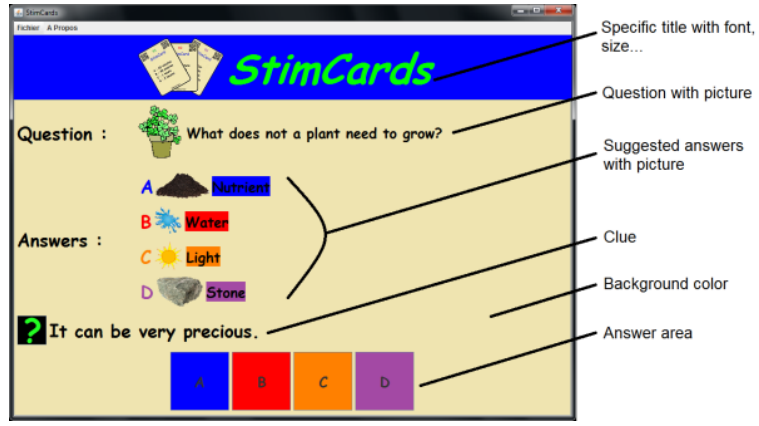

Fig. 3. A loaded card example in StimCards Graphical User Interface
question.There is also a configuration XML file which contains data about the frame. For example, it is possible to change the logo and the title ("StimCards"), its font name, size and color. This configuration XML file contains data about background and foreground color as well as the police names, sizes and colors of all different text displayed by the interface.

StimCards Graphical User Interface can be standalone. It means that users load some XML files from the menu bar. They answer with the four buttons from the answer area. A message appears to indicate whether the answer is correct.

\section{StimCards Structure}

It is possible to create different game structures according to the active digital devices. It is interesting because users can have a personalized interaction with the system. Some input and output devices can be easily added. Thus, users choose their computing interlocutor and the way they answer the question.

This flexibility is possible because StimCards is an instance of the ArCo architecture (Architecture for the Artificial Companion). In this context, the Artificial Companion is a set of different digital devices which are connected together and which collaborate to assist humans in their daily life. Figure 4 shows its organization. An end-user is surrounded by numerous digital devices which are sensors and actuators. Each sensor is managed by a computing program called Perceptive entity. Each actuator is managed by a computing program called Active entity. All the entities represent the Environment digital representation of digital devices. Perceptive entities send simple perceptions which are data about the environment. For example, it can be raw data such as a temperature or 3-D location values. It can also be data to more complex analysis such as "the person is fallen", "the person needs medicine" or "the door is opened"... All the simple perceptions are sent to a symbolic perception interpreter. It can interpret some symbolic perception scenarios to generate symbolic perceptions (high level perceptions). Each simple and symbolic perception is sent to interaction scenario interpreters. In the ArCo Architecture, interpreters are called AmbiLive. They can interpret symbolic or interaction scenarios which are written by service providers with a tool named AmbiProg. A scenario describes either creation of new perceptions (symbolic perceptions) or entities behaviors which can be triggered by the reception of specific perceptions. A service provider can

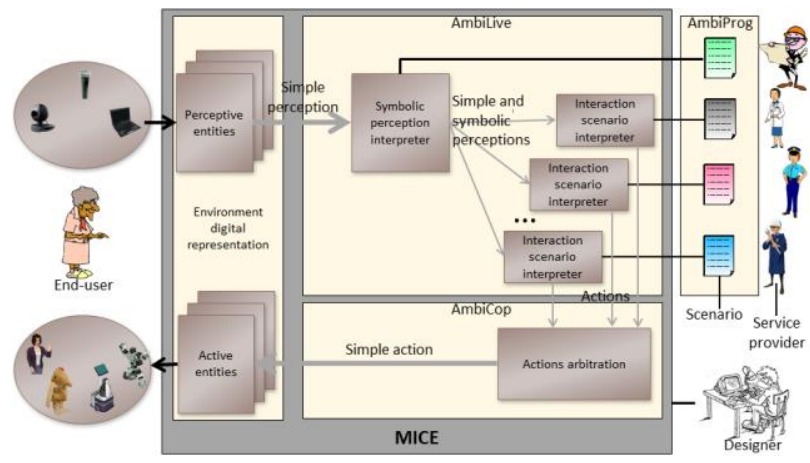

Fig. 4. The ArCo architecture 
be a doctor, a psychologist, some friends, family or the enduser him/herself. AmbiProg is a Graphical User Interface which provides a visual programming language. It is a tool which makes programming accessible for people who are unfamiliar with computer sciences.

In scenarios, entities behaviors are represented by actions. There are three categories of actions. A simple action is an order sent to a specific Active entity. A generic action is an order which is not dedicated to a specific Active entity. Numerous active entities can realize a same action (with different service qualities). The generic action is sent to the "best" one. A synchronized action is a group of orders which must start at the same time. A synchronized action is sent only if all associated active entities are "free". It means that actuators are not realizing actions.

Actions are arbitrated by a computing program called AmbiCop which detects and solves hypothetic conflicts. For example, if two simple actions must be sent to the same active entity, AmbiCop looks for their respective priority in order to send the most priority action. It sends actions to Active entities which transforms it into orders for digital devices. Perceptive and active entities, AmbiLive and AmbiCop are created by the MICE framework (Machines Interaction Control in their Environment) which allows creating and connecting modules together.

StimCards is an instance of ArCo architecture. It is possible to add perceptive and active entities to personalize the relationship with humans. It is also possible to create a great diversity of scenarios which are game scripts, in StimCards context.

\section{E. StimCards Game Scripts}

StimCards is configurable because users can create their own game scripts with AmbiProg. Figure 5 shows its organization. It is composed of three main parts. The first part is a classical menu. The second part is the programming area. The program (script) is built on a grey line, from the left to the right. It represents a sort of timeline: a branch. A program can be constructed with drag and drop, by dragging elements from the third part and dropping them in the second part. The third part contains all available elements which can be used in a script, in a tree. There are four kinds of elements: perceptions, actions, programming elements and macros.

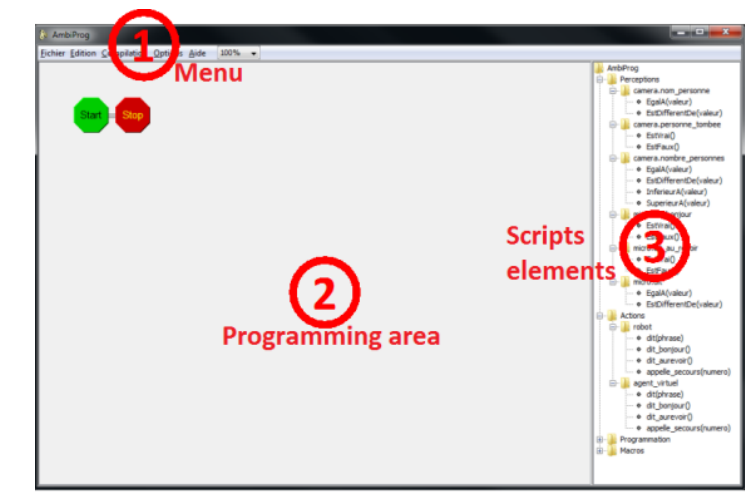

Fig. 5. AmbiProg organization
Figure 6 shows a short script example. It represents the beginning of a game session. When someone wants to play, he/she takes place and says "hello". A robot and a virtual character, which assist the gamer during the game, answer him/her by saying "hello" too.

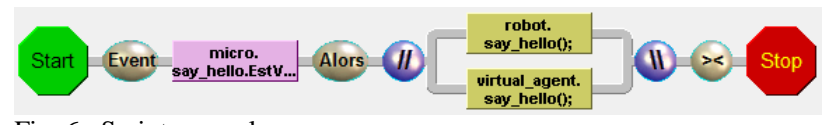

Fig. 6. Script example

\section{STIMCARDS ACCEPTANCE}

\section{A. Previous experiments}

As shown in Figure 1, we previously realized four experiments. Two experiments evaluated AmbiProg, which was positively perceived by participants [4][5]. They easily created scenarios. We concluded that AmbiProg could be an efficient "all audience" tool which could allow everyone to control easily a digital environment. Two other experiments investigated the use of different output devices as companion for the participants [6][7]. The objective was to determine whether children and seniors had a favorite companion to interact with StimCards. Results revealed that children preferred to interact with robots. Concerning seniors they preferred to interact with the computer because they considered that the robot was useless. This is not surprising as the robot did not move.

\section{B. Experimentation}

Two experimentations evaluated StimCards acceptance. Is StimCards an interesting game for people? Do people enjoy playing with StimCards? Is it easy to play with it?

The first one was realized by 27 girls and 25 boys aged between 10 and 11 years old (mean 10.3 years old) in a school. The second one was realized by 16 women and 2 men aged between 63 and 88 years old (mean 75.2 years old) in a laboratory place. The objective was to confirm whether StimCards is "all audiences" and to evaluate whether StimCards interests people. This experimentation explored if there were significant differences according to class age or gender.

Experimentations were realized in an isolated room. Figure 7 shows the materials used by children and seniors. In both cases, StimCards and the camera view were displayed on a computer. Some playing cards were made available for participants. To play, children had to position cards in the black box while seniors had to show cards in front of the camera. To answer, children used a tactile tablet while seniors used an "answer box" made with a wireless keypad. Experimental settings were not strictly similar because the game was adapted to children and seniors skills and autonomy.

At the beginning of a game session, StimCards interlocutor (robot, virtual agent or computer) explained to participants how to play. Then, participants were asked to play alone. Each child played four sessions and each senior played three sessions. At the end of all sessions, participants had to 

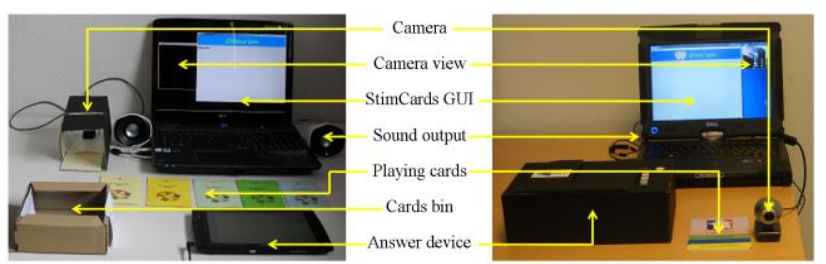

Fig. 7. Organization of StimCards acceptance experimentation

answer a questionnaire (Table I). Questions were different, according to participants' age, but their meanings were similar.

TABLE I.

QUESTIONS ASKED TO PARTICIPANTS

\begin{tabular}{|c|l|l|}
\hline $\mathbf{N}$ & \multicolumn{1}{|c|}{ Children } & \multicolumn{1}{c|}{ Seniors } \\
\hline 1 & $\begin{array}{l}\text { Did you enjoy playing with } \\
\text { StimCards? }\end{array}$ & $\begin{array}{l}\text { I appreciated playing with } \\
\text { StimCards. }\end{array}$ \\
\hline 2 & $\begin{array}{l}\text { Would you like to have } \\
\text { StimCards at home? }\end{array}$ & $\begin{array}{l}\text { I would like to use StimCards in } \\
\text { the future. }\end{array}$ \\
\hline 3 & $\begin{array}{l}\text { Were the game rules easy to } \\
\text { understand? }\end{array}$ & I think the game rules were easy. \\
\hline 4 & $\begin{array}{l}\text { Do you think computer, robot or } \\
\text { virtual character timely spoke or } \\
\text { move? }\end{array}$ & $\begin{array}{l}\text { The computer, the virtual } \\
\text { character or the robot timely } \\
\text { spoke to say correct information. }\end{array}$ \\
\hline 5 & $\begin{array}{l}\text { Would you like to be able to } \\
\text { decide whenever the computer, } \\
\text { robot or virtual character has to } \\
\text { make movement or to speak? }\end{array}$ & $\begin{array}{l}\text { It could be interesting to be able } \\
\text { to change the game script (to } \\
\text { decide pronounced sentences, } \\
\text { moment to speak, number of } \\
\text { asked questions...). }\end{array}$ \\
\hline 6 & $\begin{array}{l}\text { Would you like that the } \\
\text { computer, robot or virtual } \\
\text { character was personal (adapted } \\
\text { to you) }\end{array}$ & $\begin{array}{l}\text { It could be interesting the } \\
\text { interlocutor speak to me in a } \\
\text { personal way, with empathy, } \\
\text { emotions... }\end{array}$ \\
\hline
\end{tabular}

Data analysis used Minitab 15॰ software. The accepted P level was 0.05. Data collected were nominal (e.g. gender, class age) and ordinal (e.g. score on Likert scale). As our data were not normally distributed, we used nonparametric statistical tests to answer to our study's aims: Mann-Whitney $\mathrm{U}$ test, chi-square test.

Figure 8 shows questionnaire results. Answers given by children and seniors were almost similar. Significantly, children enjoyed playing with StimCards (strongly agree; $\mathrm{X}^{2}=86.8, \mathrm{p}<0.001$ ). They would like to have this game at home (strongly agree; $\mathrm{X}^{2}=61.8, \mathrm{p}<0.001$ ). The game rules were judged easy (strongly agree; $\mathrm{X}^{2}=53.6, \mathrm{p}<0.001$ ). Concerning the game scenario, children thought that the HGI timely spoke and move (strongly agree; $\mathrm{X}^{2}=21.2, \mathrm{p}<0.001$ ). The majority of children indicated that they wanted to be able to decide whenever the HGI had to make movement or to speak (strongly agree; $\mathrm{X}^{2}=31.7, \mathrm{p}<0.001$ ). However, this question was contrasted because the second more frequent given answer was "strongly disagree". Finally, children wanted that the HGI were personalized (strongly agree; $\mathrm{X}^{2}=69.7, \quad \mathrm{p}<0.001$ ). Significantly, seniors appreciated playing with StimCards (strongly agree and agree; $\mathrm{X}^{2}=23.8$, $\mathrm{p}<0.001$ ), estimated that the game rules were easy to understand (strongly agree; $\mathrm{X}^{2}=54.2, \mathrm{p}<0.001$ ), thought that computer robot or virtual character timely spoke or move (strongly agree and agree; $\mathrm{X}^{2}=27.6, \mathrm{p}<0.001$ ). Such difference was not observed for questions 2, 5 and 6 (all chi-

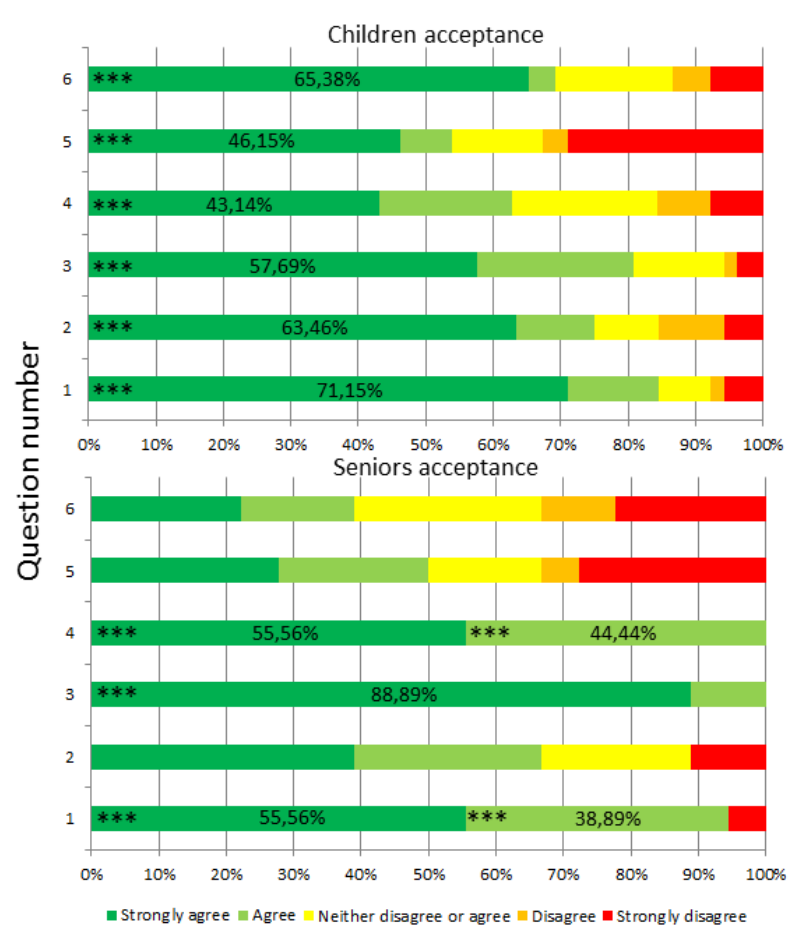

Fig. 8. Children and seniors StimCards acceptance.

Significance level: * for $\mathrm{p}<0.05, * *$ for $\mathrm{p}<0.01$ and $* * *$ for $\mathrm{p}<0.001$

square tests, $p>0.05$ ). Age and gender effects were here explored. Seniors were more prone to answer "strongly agree" and "agree" on questions 3 and 4 than children $(\mathrm{U}=1690, \mathrm{p}=0.037, \mathrm{U}=1704, \mathrm{p}=0.057)$. However, the reverse was observed for question $6(\mathrm{U}=2046.5, \mathrm{p}=0.007)$. No difference according to gender was noticed (All MannWhitney U-tests $\mathrm{p}>0.05$ ).

\section{CONCLUSION}

This paper presents StimCards, a new Question and Answer game which was applied to cognitive stimulation in the Robadom project. StimCards distinguishes from other ones because users could (1) design different game structures according to available devices, (2) enrich the game creating new questions which are immediately and easily taken into account in StimCards, (3) create game scripts which make the game totally personalized (i.e. StimCards provides AmbiProg, a Graphical User Interface with a visual programming language). Taken together, our results suggest that StimCards is adapted for a broad population from young to old people, and gender does not seem to be a decisive factor to choose a digital partner.

This paper is the final paper of a six experiments series. Two experiments evaluated the creation of scenarios, two other evaluated the preferred users' interlocutor, and two other evaluated StimCards acceptability (Figure 1). Results showed that children could easily create new scripts with AmbiProg even if they are not expert. Thus, they may represent a majority of people. But a new experiment should be realized with seniors, because of their specificities (e.g. reluctant to technology). Thus, it allows us to check if they are able to create new scripts too and if they are interesting in doing it. Limitations of our study may be the design 
differences according to age groups, e.g. robot was motionless with seniors. That is why a new experiment will be realized to compare a robot with and without motion to determine the significant part of motion. Is it possible that the seniors judge a robot useful because it expresses motions, emotions? At last, StimCards is positively accepted by children and seniors, suggesting a broad acceptance across ages.

Our six experiments lead to the following general conclusion. (1) A game should propose several partners to interact with people. In this way, people are really active because they can decide of their configuration and have a personalized game. Thus, it avoids game lassitude. (2) People can be really involved if they program their own system. It is important for acceptability that people have decision power. If people really decide, they participate to the system, they understand it, know it and consequently accept it. (3) People should not be underestimated. Everyone has the skill to program a digital environment. Our tool, AmbiProg proposes a visual programming language so easy to manipulate that children can create scenarios. People need to build their own system. (4) Seniors seem to be more passive or hesitant than children to take in hand modifications. Either it is explained by the fact that they are not familiar with technology or it indicates that seniors and children do not have the same needs (explanations are not exclusive). In all cases, results seem to indicate that seniors are not reluctant to technology if it is useful.

\section{REFERENCES}

[1] V. Fuchsberger, "Ambient assisted living: elderly people's needs and how to face them," in $S A M E$ '08, 2008, pp. 21-24.

[2] M. Chetouani, Y.-H. Wu, C. Jost, B. Le Pevedic, C. Fassert, V. Cristancho-Lacroix, S. Lassiaille, C. Granata, A. Tapus, D. Duhaut, and others, "Cognitive services for elderly people: the ROBADOM project," in ECCE workshop: Robots that care, Delf, Netherlands, 2010.

[3] M. Weiser, "The computer for the 21st century," Scientific American, vol. 265, no. 3, pp. 94-104, 1991.

[4] C. Jost, B. L. Pévédic, and D. Duhaut, "Creating Interaction Scenarios With a New Graphical User Interface,” arXiv:1206.3001, Jun. 2012.

[5] C. Jost, B. Le Pévédic, and D. Duhaut, "ArCo: an architecture for children to control a set of robots," presented at the 21st IEEE International Symposium on Robot and Human Interactive Communication, Versailles, 2012, p. 7.

[6] C. Jost, V. Andre, B. Le Pevedic, A. Lemasson, M. Hausberger, and D. Duhaut, "Ethological evaluation of human-robot Interaction: Are children more efficient and motivated with computer, virtual agent or robots?," in IEEE International Conference on Robotics and Biomimetics ROBIO, Guangzhou, China, 2012, pp. 1368-1373.

[7] J. Wrobel, Y. H. Wu, H. Kerhervé, L. Kamali, A. S. Rigaud, C. Jost, B. Le Pévédic, and D. Duhaut, "Effect of agent embodiment on the elder user enjoyment of a game," in the Sixth International Conference on Advances in Computer-Human Interactions, ACHI, Nice, France, 2013, pp. 162-167.

[8] C. Jost, B. Le Pevedic, and D. Duhaut, "Robot is best to play with human!," in 21st IEEE International Symposium on Robot and Human Interactive Communication RO-MAN, Saint Quentin En Yvelines, France, 2012, pp. 634-639.

[9] S. Pesty and D. Duhaut, "Acceptability in interaction: From robots to Embodied Conversational Agents," in GRAPP International Conference on Computer Graphics Theory and Applications, Algarve, Portugal, 2011.
[10] P. Legris, J. Ingham, and P. Collerette, "Why do people use information technology? A critical review of the technology acceptance model," Information \& Management, vol. 40, no. 3, pp. 191-204, Jan. 2003.

[11] F. D. Davis, "Perceived usefulness, perceived ease of use, and user acceptance of information technology," MIS quarterly, vol. 13, no. 3, pp. 319-340, 1989.

[12] V. Venkatesh, C. Speier, and M. G. Morris, "User Acceptance Enablers in Individual Decision Making About Technology: Toward an Integrated Model," Decision Sciences, vol. 33, no. 2, pp. 297-316, Mar. 2002.

[13] W. R. King and J. He, "A meta-analysis of the technology acceptance model," Information \& Management, vol. 43, no. 6, pp. 740-755, Sep. 2006.

[14] M. Tedre, "What should be automated?," interactions, vol. 15, no. 5, p. 47, Sep. 2008.

[15] T. Klamer and S. Ben Allouch, "Acceptance and use of a zoomorphic robot in a domestic setting," in European Meetings on Cybernetics and Systems Research (EMCSR), 2010.

[16] A. Tricot, F. Plégat-Soutjis, J. F. Camps, A. Amiel, G. Lutz, A. Morcillo, and others, "Utilité, utilisabilité, acceptabilité: interpréter les relations entre trois dimensions de l'évaluation des EIAH," in Environnements Informatiques pour l'Apprentissage Humain 2003, Strasbourg, France, 2003, pp. 391-402.

[17] R. Steele, A. Lo, C. Secombe, and Y. K. Wong, "Elderly persons' perception and acceptance of using wireless sensor networks to assist healthcare," International Journal of Medical Informatics, vol. 78, no. 12, pp. 788-801, Dec. 2009.

[18] C. McCREADIE and A. Tinker, "The acceptability of assistive technology to older people," Ageing and Society, vol. 25, no. 1, pp. 91-110, Jan. 2005.

[19] J. Rico and S. Brewster, "Usable gestures for mobile interfaces," in CHI'10, Etats-Unis, 2010, p. 887.

[20] M. Tacken, F. Marcellini, H. Mollenkopf, I. Ruoppila, and Z. Széman, "Use and acceptance of new technology by older people. Findings of the international MOBILATE survey: 'Enhancing mobility in later life'," Gerontechnology, vol. 3, no. 3, Jul. 2005.

[21] M. Heerink, B. Krose, V. Evers, and B. Wielinga, "The Influence of a Robot's Social Abilities on Acceptance by Elderly Users," in $R O$ MAN 2006, Royaume-Uni, 2006, pp. 521-526.

[22] R. Berenbaum, Y. Lange, and L. Abramowitz, "Augmentative alternative communication for Alzheimer's patients and families' using SAVION," in PETRA 2011, Grèce, 2011, p. 1.

[23] V. Venkatesh and M. G. Morris, "Why don't men ever stop to ask for directions? Gender, social influence, and their role in technology acceptance and usage behavior," Management Information Systems Quarterly, vol. 24, no. 1, pp. 115-140, 2000.

[24] V. A. Vanden Abeele and V. Van Rompaey, "Introducing humancentered research to game design : designing game concepts for and with senior citizens," in CHI EA'06, Etats-Unis, 2006, p. 1469.

[25] F. Imbeault, B. Bouchard, and A. Bouzouane, "Serious games in cognitive training for Alzheimer's patients," in SeGAH 2011, Portugal, 2011, pp. 1-8.

[26] A. Brandão, L. Brandão, G. Nascimento, B. Moreira, C. N. Vasconcelos, and E. Clua, "JECRIPE: stimulating cognitive abilities of children with down syndrome in pre-scholar age using a game approach," in International Conference on Advances in Computer Entertainment Technology, Taiwan, 2010, p. 15.

[27] Z. Wei, L. Li, J. Zhu, and Z. Chi, "Games for Service Science Education," in ICSS, Chine, 2010, pp. 237-241.

[28] B. Loureiro and R. Rodrigues, "Multi-touch as a Natural User Interface for elders: A survey," in CISTI 2011, Chaves, Portugal, 2011, pp. $1-6$.

[29] A. Lazar, "Engaged learning in a computer science course," Journal of Computing Sciences in Colleges, vol. 23, no. 1, pp. 3844, 2007.

[30] G. Goth, "Brave NUI world," Communications of the ACM, vol. 54, no. 12 , p. 14, Dec. 2011.

[31] J. Jain, A. Lund, and D. Wixon, "The future of natural user interfaces," in CHI EA '11, Canada, 2011, p. 211. 